\title{
Research
}

\section{Pregnancy protection and pregnancies in women prescribed ACE inhibitors or ARBs:}

\author{
a cross-sectional study in primary care
}

\begin{abstract}
\section{Background}

The teratogenic risks of angiotensin-converting enzyme (ACE) inhibitors and angiotensin receptor blockers (ARBs) are well documented, but prescribing these in younger women in primary care is becoming increasingly frequent.

\section{Aim}

To record how frequently women of childbearing age, who are prescribed an ACE inhibitor or $A R B$, receive preconception advice and/or are prescribed contraception, and how many pregnancies, terminations, and miscarriages occur in this population. Additionally, to ascertain whether patterns in the above differ across age groups.
\end{abstract}

\section{Design and setting}

Cross-sectional study conducted among patients from 141 general practices in East London.

\section{Method}

Women aged $15-45$ years who were issued a prescription for an ACE inhibitor or ARB between 1 October 2018 and 1 January 2019 inclusive were included. An electronic search strategy was designed to extract pseudonymised data concerning preconception and contraception advice, contraception, and pregnancies from the electronic clinical system; this was applied to the selected cohort on 1 January 2019. Data were analysed in 5-year age groups.

\section{Results}

Of 302939 women aged 15-45 years, 2651 (0.9\%) were prescribed an ACE inhibitor or an ARB in a 3-month period. Of these, $2159(81.4 \%)$ had no advice and no contraception prescription recorded, 35 (1.3\%) had preconception advice recorded, and $230(8.7 \%)$ had contraception advice recorded. A total of 100 pregnancies and 21 terminations/miscarriages were recorded in the 12 months preceding the index date (1 January 2019).

\section{Conclusion}

This study found that the recording of prepregnancy advice and contraception in women of childbearing age who were prescribed an ACE inhibitor or an ARB was suboptimal; this may place women and their babies at risk of exposure to teratogens during pregnancy. The findings indicate that there is a need for improved safety strategies based in primary care.

\section{Keywords}

angiotensin-converting enzyme inhibitors; angiotensin receptor blockers; contraception;

female; pregnancy; primary health care.

\section{INTRODUCTION}

The global obesity epidemic has caused increasing prevalence of diabetes at younger ages and a sixth of people with hypertension are now aged $<45$ years. ${ }^{1-4}$ The National Institute for Health and Care Excellence (NICE) and the British and Irish Hypertension Society (BIHS) currently recommend angiotensin-converting enzyme (ACE) inhibitors or angiotensin receptor blockers (ARBs) as first-line management for patients aged $<55$ years with hypertension., 5 These medicines are also frequently prescribed for diabetes.?

ACE inhibitors/ARBs are known to be teratogenic and some studies suggest congenital anomalies can occur with exposure in the first trimester only. ${ }^{8-11}$ With increasing rates of hypertension and diabetes at younger ages, the prescription of ACE inhibitors/ARBs in women of childbearing age is becoming more common; as such, inadvertent use of ACE inhibitors/ARBs during a pregnancy is increasing. 8,12,13 It has been reported that $16 \%$ of pregnancies in the UK are unplanned..$^{14}$ Most pregnancies are not recognised until at least halfway through the first trimester, when deleterious effects may already have occurred from ACE inhibitor/ARB exposure. 8,9,12,13,15

Indeed, delays in pregnancy confirmation result in ACE inhibitors or ARBs frequently being continued during pregnancy. ${ }^{12,13}$

E Lovegrove, BSc, BMBS, academic clinical fellow in general practice, Portsmouth Hospitals NHS

Trust, Portsmouth. J Robson, MD, FRCGP, reader in primary care; $\mathbf{P}$ McGettigan, BSc (Pharmacy), MD, FRCPI, FRACP, SFHEA, reader in clinical pharmacology and medical education, Barts and the London School of Medicine and Dentistry, Queen Mary University of London, London. Address for correspondence

Elizabeth Lovegrove, Institute of Population Health Sciences, Queen Mary University of London, Yvonne Carter Building, 58 Turner Street, London
Consequently, preventing inappropriate ACE inhibitor/ARB use during a pregnancy has to be an important current consideration, and become a key future consideration, in primary care. ${ }^{5,6}$

\section{Guideline and regulator advice}

The Medicines and Healthcare products Regulatory Agency (MHRA) and NICE advise that clinicians should inform women who are prescribed ACE inhibitors/ARBs of the teratogenic risks of these medicines. ${ }^{5,6,16}$ UK and US guidelines also advise that, if a woman with hypertension is planning a pregnancy, clinicians should discuss alternative antihypertensive medications prior to conception and, if a pregnancy occurs, the ACE inhibitor/ARB should be stopped or switched immediately.5,6,16,17 This contrasts with national guidelines from other countries, which recommend that these medicines be avoided in women of childbearing age with hypertension or only co-prescribed with contraception. ${ }^{18-24}$ Consequently, there appears to be little global consensus concerning the prescription of ACE inhibitors/ARBs in women of childbearing age.

\section{Guideline compliance}

A 2008 study found that nearly half of women referred to a specialist hypertension clinic were prescribed an ACE inhibitor/ARB; $70 \%$ of these were using non-permanent contraception, no contraception, or their

E1 2AB, UK

Email: Elizabeth.lovegroveanhs.net

Submitted: 3 October 2019; Editor's response: 8 November 2019; final acceptance: 5 March 2020

\section{(C)British Journal of General Practice}

This is the full-length article (published online 6 Oct 2020) of an abridged version published in print. Cite this version as: $\mathbf{B r} \mathbf{J}$ Gen Pract 2020; DOI: https://doi.org/10.3399/bjgp20X712997 


\section{How this fits in}

Exposure to angiotensin-converting enzyme inhibitors or angiotensin receptor blockers during pregnancy is associated with teratogenic risk to the fetus. This study shows that the recording of pre-pregnancy advice and contraception in women of childbearing age, who are prescribed such medicines, is suboptimal and a number of pregnancies occur in this population. As this may place women and their babies at risk of exposure to teratogens, there is a need for significant improvements in the care of these patients.

contraception status was unknown. ${ }^{25}$ In a US study, only $11.7 \%$ of women of childbearing age with hypertension, hypercholesterolaemia, or diabetes had evidence of giving informed consent to be prescribed an ACE inhibitor ARB, or statin, having been informed of the risk of adverse fetal effects. ${ }^{26}$

Despite exposure concerns, there have been no studies, of which the authors are aware, to assess guideline compliance in the UK including rates of pre-pregnancy advice and contraception prescriptions or the, possibly associated, pregnancy or miscarriage rate.

The aim of this study was to fill this knowledge deficit, in the context of general practice, because in the UK it is the source of most ACE inhibitor/ARB and contraception prescriptions and, often, the most appropriate environment in which to offer pre-pregnancy advice.

The study aimed to ascertain:

\section{Table 1. Age and ethnicity of the study population ( $N=2651$ )}

\begin{tabular}{lc} 
Characteristic & $\boldsymbol{n}(\%)$ \\
\hline $\begin{array}{l}\text { Age group } \\
\text { 15-19 years }\end{array}$ & $19(0.7)$ \\
20-24 years & $34(1.3)$ \\
25-29 years & $93(3.5)$ \\
30-34 years & $238(9.0)$ \\
$35-39$ years & $626(23.6)$ \\
40-45 years & $1641(61.9)$ \\
\hline Ethnicity & \\
Asian/Asian British & $1641(61.9)$ \\
White/other white & $342(12.9)$ \\
Black African/black Caribbean/ & $334(12.6)$ \\
black British & \\
\hline
\end{tabular}

${ }^{a}$ Range: $15-45$ years; mean age: 39.6 years. ${ }^{b}$ Small numbers of women listed under various ethnicities, or women with no recorded ethnicity, made up the remaining $12.6 \%$ ( $n=334$ ) of the study population's listed ethnicities.

\section{Data collection}

All 141 GP practices included in the study use EMIS Web, an electronic, integrated clinical IT system. Clinical information and all GP-issued prescriptions are coded and recorded by the healthcare provider, using the Read code system. Read codes are a coded thesaurus of clinical words and phrases that enable information to be coded and searched for in a standard manner across primary and secondary healthcare systems in the UK. ${ }^{27}$ De-identified Read-coded information was centrally extracted from GPs' electronic clinical systems and no other healthcare systems were accessed. Free-text information was not available. Data were accessed, encrypted, and securely stored by the Clinical Effectiveness Group (CEG) at Queen Mary University of London. Pawa et al have provided a detailed description of the types of databases held by the CEG, and its role in facilitating information sharing between CCGs and practices. ${ }^{28}$

\section{Study population}

Female patients aged $15-45$ years were selected from all patients registered at the 141 practices. A British National Formulary (BNF) code pertaining to an ACE inhibitor/ ARB prescription within 3 months prior to the index date (that is, from 1 October 2018 until the index date of 1 January 2019] was searched in the electronic medical record (EMR) for each selected patient. Women who had a recorded ACE inhibitor/ ARB prescription within this time frame were selected for inclusion in the study; of those, women with a recorded Read code for a previous hysterectomy or sterilisation procedure were then excluded. The Read codes used to identify patients for exclusion are detailed in Supplementary Table S1.

Read codes for the information elements listed below (see Supplementary Tables S2S4) were then searched for within a range of time frames, and extracted from the EMR of each patient in the study cohort on the index date (1 January 2019):

- ethnicity: most recent code;

- comorbidities, including hypertension, diabetes, heart failure, and chronic kidney disease (CKD): most recent code;

- ACE inhibitor/ARB name and dose: most recent code;

- preconception advice: coded in the 12 months preceding the index date;

- contraception advice: coded in the 12 months preceding the index date;

- oral contraception, transdermal 


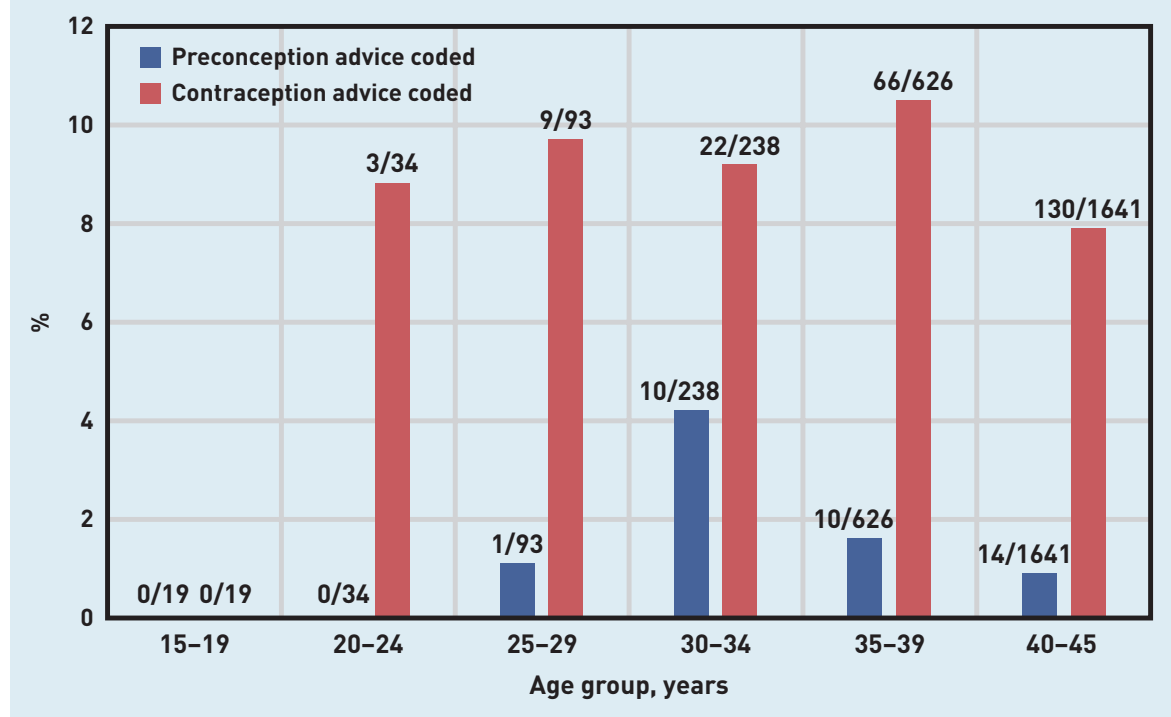

Figure 1. Percentage of each age group for whom preconception or contraception advice was recorded during the 12 months preceding the index date.

Figure 2. Percentage of each age group for whom a LARC or an oral/transdermal contraceptive was recorded in the relevant time frames. $L A R C=$ long-acting reversible contraception.

contraception, or long-acting reversible contraception (LARC): code searched for within various time frames, ranging from a few months to several years (see Supplementary Tables S3 and S4);

- pregnancy: coded in the 12 months preceding the index date; and

- termination/miscarriage: coded in the 12 months preceding the index date.

Each included patient was allocated a pseudonymised identifier. The Read codes present were recorded against each pseudonymised identifier. There were no updates to the database during the data analysis.

Sex, age, and any prescribed medications are recorded automatically and consistently in the patient's medical record in the EMIS

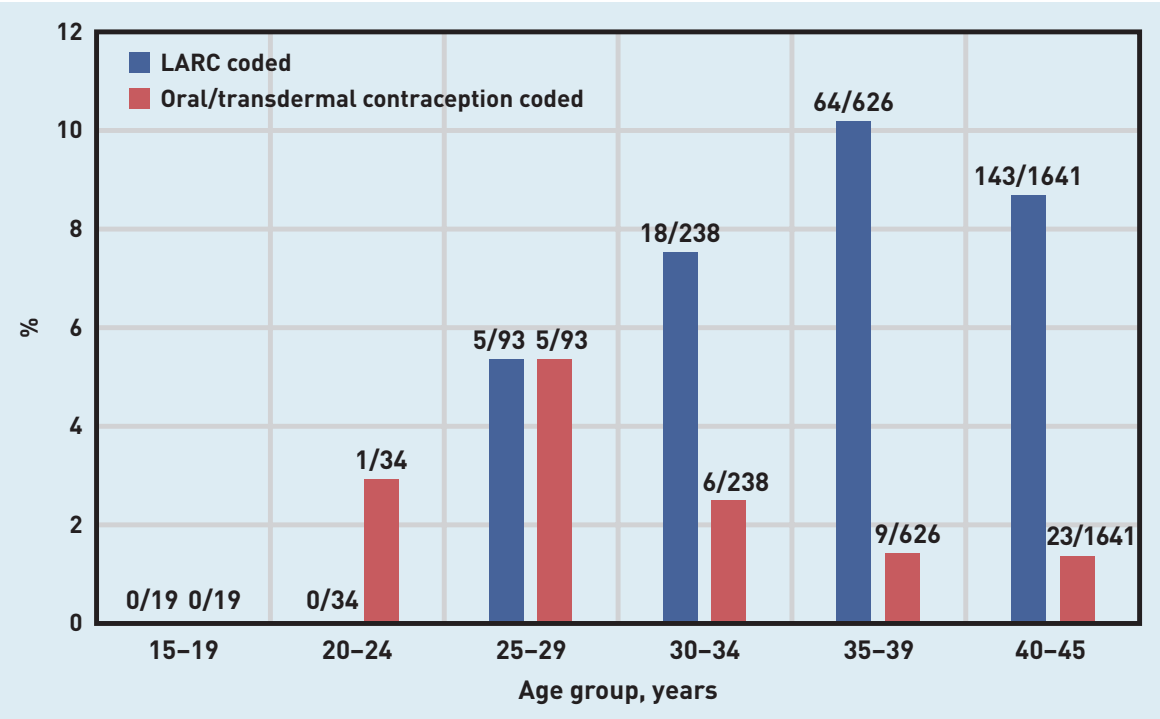

Web system. Data may be missing for aspects of a patient's health care, if that care was accessed outside of the primary care setting (for example, in sexual-health centres) or if the data were recorded only as a free-text entry and not coded. This is acknowledged as a common problem in the use of primary care datasets. ${ }^{29}$

\section{Data analysis}

Data were analysed using Microsoft Excel for Mac (version 16.24). Univariate descriptive statistics were used along with 5 -year age groups. Averages are presented as the mean, unless otherwise stated.

\section{RESULTS}

\section{Study sample}

Table 1 outlines the age and ethnicity of the study population. See Supplementary Table S5 for absolute numbers of women in each age group.

\section{Population comorbidities and ACE inhibitor/ARB prescriptions}

Among the 2651 women included in the study, 2054 (77.5\%) had a recorded diagnosis of hypertension, 1000 (37.7\%) had one for diabetes, 147 (5.5\%) had one for CKD, and 57 (2.2\%) had one for heart failure. Ramipril was prescribed to 1538 (58.0\%) women, losartan to $470(17.7 \%)$ women, and lisinopril to 212 (8.0\%) women; $16.3 \%$ of women used others (data not shown).

\section{Preconception and contraception advice,}

\section{and methods of contraception}

Figure 1 shows the percentage of women in each age group for whom preconception or contraception advice had been recorded. A Read code concerning preconception advice and contraception advice was recorded in the 12 months preceding the index date in $35(1.3 \%)$ women and $230(8.7 \%)$ women, respectively.

Figure 2 shows the percentage of the population, within each age group, that had a LARC or an oral/transdermal contraceptive recorded in the relevant time frames. In total, 230 (8.7\%) women had a LARC prescription recorded in the relevant time frame; for these women, the following methods were used:

- intrauterine device $(n=96,41.7 \%)$;

- intrauterine system ( $n=65,28.3 \%)$;

- subcutaneous implant ( $n=45,19.6 \%)$; and

- depot progestogen injection $(n=24$, $10.4 \%)$ 


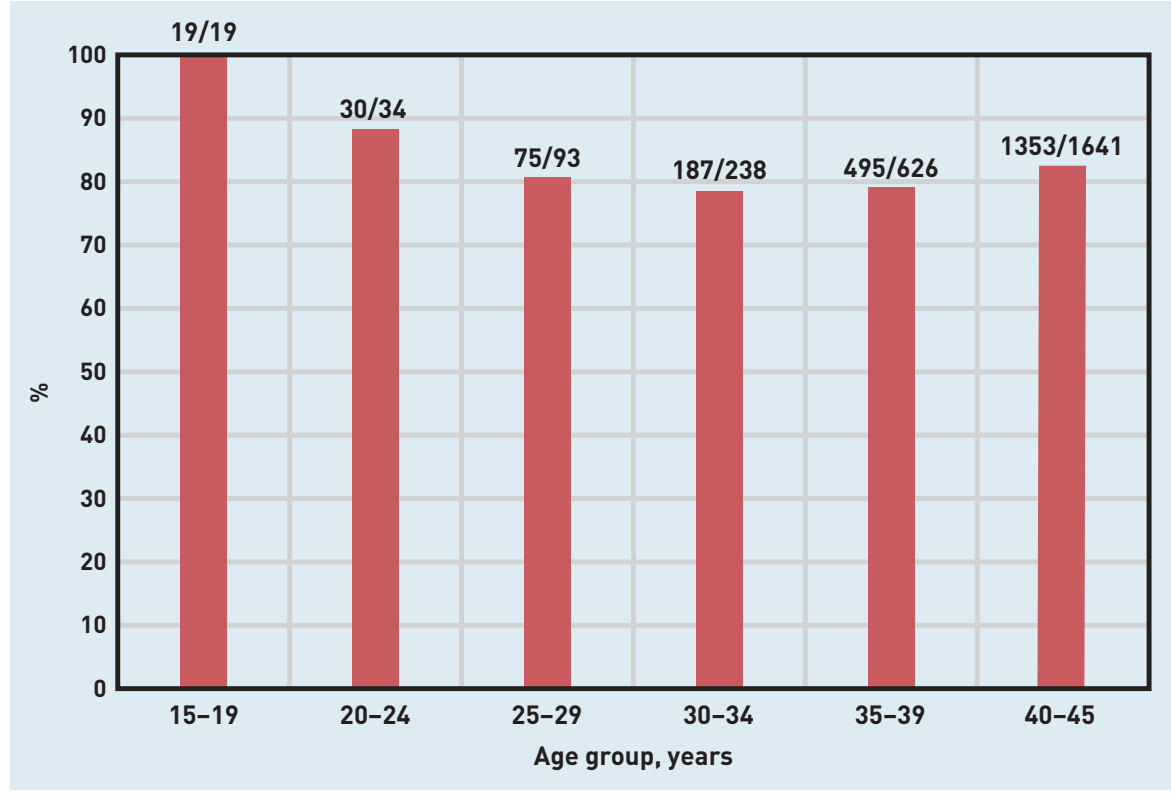

Figure 3. Percentage of each age group for whom no preconception advice, contraception advice, or contraception was recorded in the relevant time frames.
Of the total cohort of 2651 women, 44 $(1.7 \%)$ had a prescription for an oral or transdermal contraceptive recorded in the 6 months preceding the index date; of these, 42 (95.5\%) had the combined oral contraceptive pill recorded and two (4.5\%) had a transdermal contraceptive recorded.

Figure 3 shows the percentage of women in eachage group for whom no preconception advice and no contraception advice had been recorded in the 12 months preceding the index date, and no contraception had been recorded in the time frames outlined in Supplementary Tables S3 and S4.

\section{Pregnancy and termination of pregnancy}

In total, 100 pregnancies and 21 terminations/miscarriages were recorded in the whole study population

\section{Table 2. Recorded preconception advice, contraception advice, pregnancies, and terminations/miscarriages}

\begin{tabular}{|c|c|c|c|}
\hline Population & Time frame & $\begin{array}{l}\text { Recorded } \\
\text { pregnancies, } \\
n(\%)\end{array}$ & $\begin{array}{c}\text { Recorded terminations/ } \\
\text { miscarriages, } \\
n(\%)\end{array}$ \\
\hline All women $(n=2651)$ & 12 months preceding the index date & $100(3.8)$ & $21(0.8)$ \\
\hline All women $(n=2651)$ & $\begin{array}{l}\text { Following most-recent ACE } \\
\text { inhibitor/ARB prescription }\end{array}$ & $13(0.5)$ & $4(0.2)$ \\
\hline $\begin{array}{l}\text { Women with no recorded } \\
\text { advice or contraception } \\
\text { (n=2159) }\end{array}$ & 12 months preceding the index date & $63(2.9)$ & $16(0.7)$ \\
\hline $\begin{array}{l}\text { Women with no recorded } \\
\text { advice or contraception } \\
\text { (n=2159) }\end{array}$ & $\begin{array}{l}\text { Following most } \\
\text { recent ACE inhibitor/ } \\
\text { ARB prescription }\end{array}$ & $11(0.5)$ & $3(0.1)$ \\
\hline
\end{tabular}

$A C E=$ angiotensin-converting enzyme. $A R B=$ angiotensin receptor blocker.
( $n=2651$ ) during the 12 months preceding the index date (Table 2). Based on the Read codes, 58 pregnancies were 'definite' and 42 'inferred' (Supplementary Table S6). Thirteen pregnancies and four terminations/miscarriages followed the most recent prescription of an ACE inhibitor or ARB (Table 2).

A total of $2159(81.4 \%)$ of the entire study population had neither preconceptual or contraception advice recorded in the 12 months preceding the index date, nor any form of contraception recorded within the relevant time frames. Within these women, there were 63 recorded pregnancies and 16 recorded terminations/ miscarriages. In those women for whom no advice or contraception was recorded, 11 pregnancies and three terminations/ miscarriages were recorded, respectively, following the most-recent prescription for an ACE inhibitor or ARB.

Figure 4 shows the percentage of women in each age group for whom a pregnancy or a termination/miscarriage had been recorded in the 12 months preceding the index date.

\section{DISCUSSION}

\section{Summary}

Among 2651 women of childbearing age with a prescription for an ACE inhibitor or ARB, $81.4 \%$ had no recorded preconception or contraception advice in the 12 months preceding the index date and no recorded contraception prescription. Just $1.3 \%$ and $8.7 \%$ of the population had preconception and contraception advice recorded, respectively, in the 12 months preceding the index date and $8.7 \%$ and $1.7 \%$ had a prescription for a LARC or oral/transdermal contraceptive recorded, respectively, in the relevant time frames. This apparent lack of provision for delivering pre-pregnancy safety advice may increase the risk of a woman conceiving while prescribed an ACE inhibitor or ARB and, as such, also increase the risk of the fetus being exposed to teratogens.

Indeed, women without pregnancyprevention interventions are likely to be most at risk of conceiving. ${ }^{30} \mathrm{~A}$ total of 100 pregnancies and 21 terminations/ miscarriages were recorded during the 12 months examined, while $13 \%$ and $19 \%$ of these pregnancies and terminations/ miscarriages, respectively, were recorded within 3 months of the woman receiving a prescription for an ACE inhibitor or ARB. As such, pregnancy exposure to ACE inhibitors or ARBs remains a current and important hazard to women and their unborn babies. 


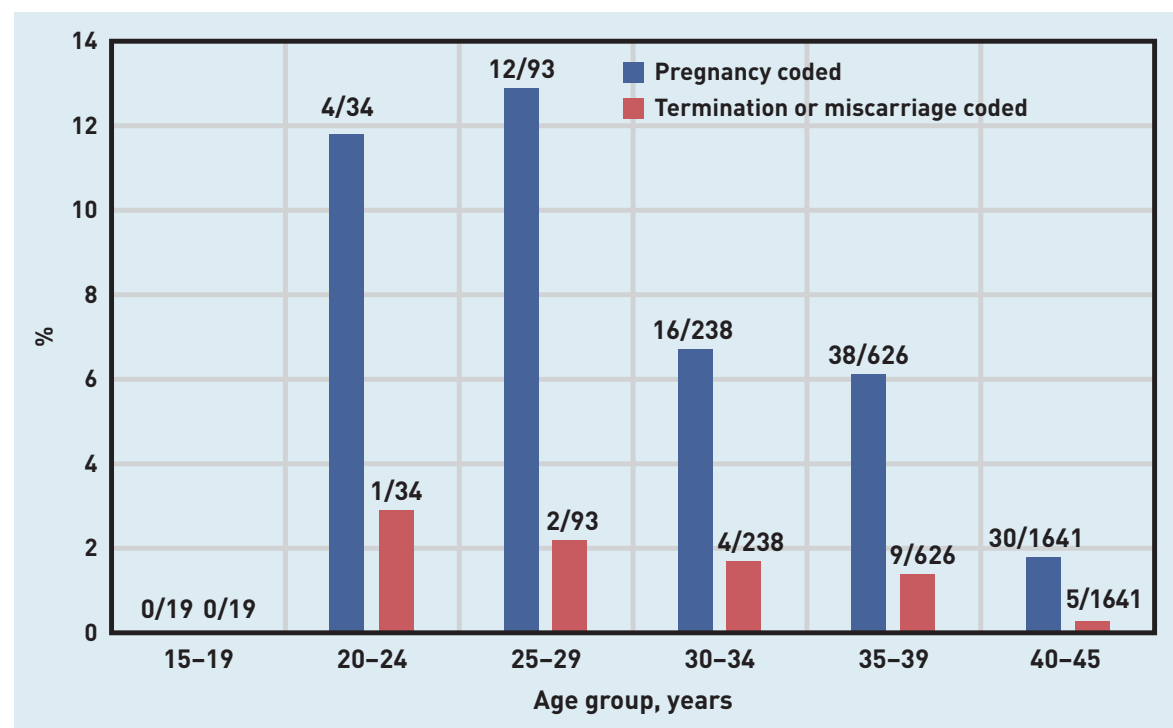

Figure 4. Percentage of each age group, for whom either a pregnancy or a termination/miscarriage was recorded in the 12 months preceding the index date.

\section{Strengths and limitations}

This study provides a contemporary perspective on pregnancy preparation in women of childbearing age who have been prescribed anACE inhibitor orARB. Although the sample was drawn from a relatively large socially and ethnically diverse population without prior selection - thereby providing a real-world cohort - the population was drawn from areas of deprivation and was ethnically diverse, therefore the results may not be generalisable, especially to non-urban settings, and the study requires replication elsewhere. In spite of this, the patient demographics and comorbidities were comparable with those in existing literature. .5, $26^{26}$

The use of the Read code system a single, electronic, consistent coding system that allows for universal access to patients' EMRs - is a significant strength. Furthermore, all prescribed medicines are electronically prescribed by GPs; therefore, the data presented is an accurate representation of prescribing. However, a small number of patients may choose not to have their medicine dispensed by the pharmacy - the authors were unable to account for these patients in this study. GPs may not always code the advice they give, and some women may access care elsewhere; as a result, the findings presented here may underestimate the advice offered about potential pregnancy/ pregnancy risks, whether planned or not

Indeed, the results highlight a key medicolegal issue: if advice is not being recorded or coded correctly, should an adverse event occur, the clinician would have very little evidence supporting their claim that advice was given.
As this study only examined prescribing between 1 October 2018 and 1 January 2019 inclusive, those women who were prescribed an ACE inhibitor or ARB earlier in the year, and may have had a pregnancy exposed to these teratogens, were not included; this may underestimate potential exposure. The authors searched for parent Read codes rather than individual daughter Read codes, for example, the 'gravida' parent code was searched for as an 'inferred' pregnancy code, which includes all values of gravida, including gravida 0 . Therefore, it should be noted that use of a parent code in this instance may have resulted in a slightly higher number of pregnancies being recorded than actually occurred.

\section{Comparison with existing literature}

The findings of this study are in agreement with previous international studies that suggest care is suboptimal. 8,13,16,26,31 The most recent UK study, of which the authors are aware, dates from 2008; it found low levels of contraception use in a hospital clinic population of hypertensive women of childbearing age taking ACE inhibitors or ARB who potentially could become pregnant (that is, they were premenopausal and neither they nor their partners were sterilised). ${ }^{25}$ The findings presented here suggest there has been little improvement in pre-pregnancy care for women prescribed an ACE inhibitor or ARB in the decade since then.

The study presented here found that younger women were least likely to receive preconception advice or prescribed contraception (Figure 3).

A recent British population-wide survey found that those aged $<25$ years have the highest rates of unplanned pregnancy and potentially women in this age group who are taking ACE inhibitors or ARBs are similar to this age group as a whole. ${ }^{14}$ The recording of advice and contraception also decreased for women aged $\geq 35$ years, who formed a larger at-risk group as they are more likely to be prescribed an ACE inhibitor/ARB. UK pregnancy rates in those aged $>40$ years are increasing rapidly. ${ }^{32}$ The findings presented here show that women aged 40-45 years had the second highest absolute number of pregnancies and terminations/miscarriages lalthough not the highest proportion).

Although some age differences were observed, overall, all women of childbearing age who were prescribed an ACE inhibitor or ARB had very low levels of recorded pregnancy advice, associated 
with considerable numbers of pregnancies and potential exposure to teratogenic medications. Previous studies suggest a lack of time, financial incentive, and clinician knowledge are responsible for poor pregnancy preparation. ${ }^{33}$

International guidelines recommend that the prescription of an ACE inhibitor or ARB is avoided in young women, contraception is co-prescribed, or 'adequate precautions' are taken against pregnancy. ${ }^{18-22}$ European Society of Cardiology guidelines suggest the use of ACE inhibitors and ARBs in women without reliable contraception is a possible contraindication. .3,24 $^{2}$

New NICE guidance includes no recommendation that pre-pregnancy planning/advice or contraception should be provided, and recommends the use of enalapril (an ACE inhibitor) as a first-line management option in the post-partum period for chronic hypertension; ${ }^{5}$ this is despite an MHRA warning, advising against ACE inhibitor or ARB use in the early postpartum period because of possible neonatal hypotension. ${ }^{34}$ Furthermore, NICE advises that, in women prescribed an ACE inhibitor or ARB for hypertension, clinicians should discuss suitable alternative medicines if pregnancy is planned..$^{5}$ In contrast, for women prescribed an ACE inhibitor or ARB for other conditions such as diabetes, a discussion about alternatives is recommended, irrespective of pregnancy plans. ${ }^{5}$ Inconsistency in national and international guidelines may also preclude optimal delivery of effective pregnancy preparation provisions to these women, and guidelines and improvement programmes require system-wide interventions for maximum impact. ${ }^{35}$

Trials of decision-support systems and ad hoc patient reviews have demonstrated no improvement in prescribing of potentially teratogenic medications to women who could become pregnant. ${ }^{36}$ The failure to provide stronger system-wide measures to prevent pregnancy exposure to ACE inhibitors and ARBs is in sharp contrast with recent MHRA safety initiatives regarding the highly teratogenic drug, valproate, which have generated a system-wide approach to active engagement by patients, their hospital specialists, and GPs. ${ }^{37}$

\section{Implications for research and practice}

As mentioned previously, low levels of recorded pre-pregnancy advice and contraception may place women who are prescribed an ACE inhibitor or ARB at high risk of pregnancy exposure to these teratogens. Teratogenic risks of ACE inhibitors and ARBs are well documented, and the prescribing of these medications in women of childbearing age in primary care is becoming increasingly frequent. As this study found that the recording of pre-pregnancy advice and contraception in such women was suboptimal and has not improved over the last decade, primarycare-based improvement strategies are required. Patient-held records, signed consent relating to the understanding of pregnancy risks, electronic-alert and virtual review systems, clinician education, prescribing incentives, and patient education materials may contribute to safer systems for women of childbearing age prescribed an ACE inhibitor or an ARB.

The Cumberlege report has recently expressed concern about exposure to teratogenic medicines in pregnancy. ${ }^{38}$

Future research could be undertaken in large representative national general practice datasets such as QResearch, The Health Improvement Network (THIN), or Clinical Practice Research Datalink (CPRD) to further estimate the scale of possible pregnancy exposure to ACE inhibitors/ ARBs, as well as additional research on GPs' knowledge of prescribing hazards in pregnancy.

The authors would like to thank Ms Isabel Dostal for completing the data extraction and are grateful to the GPs and their registered populations in East London who made this study possible by contributing to data sharing with the Clinical Effectiveness Group, Queen Mary University of London; this allowed the group to extract the data and make it available for the purposes of improved patient care and population benefit.

\section{Discuss this article}

Contribute and read comments about this article: bjgp.org/letters 


\section{REFERENCES}

$1 \quad$ Public Health England. Health matters: combating high blood pressure. 2017. https://www.gov.uk/government/publications/health-matters-combating-highblood-pressure/health-matters-combating-high-blood-pressure laccessed 28 Sep 2020).

2. Sorof JM, Lai D, Turner J, et al. Overweight, ethnicity, and the prevalence of hypertension in school-aged children. Pediatrics 2004; 113(3 Pt 1): 475-482.

3. Saklayen MG. The global epidemic of the metabolic syndrome. Curr Hypertens Rep 2018; 20(2): 12.

4. Editor. Diabetes prevalence. Diabetes.co.uk 2019; 15 Jan: https://uww.diabetes. co.uk/diabetes-prevalence.html (accessed 28 Sep 2020).

5. National Institute for Health and Care Excellence. Hypertension in pregnancy: diagnosis and management. NG133. London: NICE, 2019. https://www.nice.org uk/guidance/NG133 (accessed 28 Sep 2020).

6. National Institute for Health and Care Excellence. Hypertension in adults: diagnosis and management. CG127. London: NICE, 2011. https://www.nice.org. uk/guidance/cg127 laccessed 28 Sep 2020).

7. National Institute for Health and Care Excellence. Drugs affecting the reninangiotensin system. Angiotensin-converting enzyme inhibitors. London: NICE, 2020. https://bnf.nice.org.uk/treatment-summary/drugs-affecting-the-reninangiotensin-system.html (accessed 28 Sep 2020).

8. Bullo M, Tschumi S, Bucher BS, et al. Pregnancy outcome following exposure to angiotensin-converting enzyme inhibitors or angiotensin receptor antagonists: a systematic review. Hypertension 2012; 60(2): 444-450.

9. Cooper WO, Hernandez-Diaz S, Arbogast PG, et al. Major congenital malformations after first-trimester exposure to ACE inhibitors. N Engl J Med 2006; 354(23): 2443-2451

10. Moretti ME, Caprara D, Drehuta I, et al. The fetal safety of angiotensin converting enzyme inhibitors and angiotensin ii receptor blockers. Obstet Gynecol Int 2012 2012: 658310 .

11. Pucci M, Sarween N, Knox E, et al. Angiotensin-converting enzyme inhibitors and angiotensin receptor blockers in women of childbearing age: risks versus benefits. Expert Rev Clin Pharmacol 2015; 8(2): 221-231.

12. Bateman BT, Hernandez-Diaz S, Huybrechts KF, et al. Patterns of outpatient antihypertensive medication use during pregnancy in a Medicaid population. Hypertension 2012; 60(4): 913-920.

13. Cea Soriano L, Bateman BT, García Rodríguez LA, Hernández-Díaz S. Prescription of antihypertensive medications during pregnancy in the UK. Pharmacoepidemiol Drug Saf2014; 23(10): 1051-1058.

14. Wellings $\mathrm{K}$, Jones $\mathrm{KG}$, Mercer $\mathrm{CH}$, et al. The prevalence of unplanned pregnancy and associated factors in Britain: findings from the third National Survey of Sexual Attitudes and Lifestyles (Natsal-3). Lancet 2013; 382(9907): 1807-1816.

15. Bowen ME, Ray WA, Arbogast PG, et al. Increasing exposure to angiotensinconverting enzyme inhibitors in pregnancy. Am J Obstet Gynecol 2008; 198(3): 291.e1-e5.

16. Medicines and Healthcare products Regulatory Agency. ACE inhibitors and angiotensin II receptor antagonists: not for use in pregnancy. 2014. https:// www.gov.uk/drug-safety-update/ace-inhibitors-and-angiotensin-ii-receptorantagonists-not-for-use-in-pregnancy (accessed 28 Sep 2020).

17. Whelton PK, Carey RM, Aronow WS, et al. 2017 ACC/AHA/AAPA/ABC/ACPM/ AGS/APhA/ASH/ASPC/NMA/PCNA Guideline for the Prevention, Detection, Evaluation, and Management of High Blood Pressure in Adults: executive summary - a report of the American College of Cardiology/American Heart Association Task Force on Clinical Practice Guidelines. Circulation 2018; 138(17): e426-e483.

18. Sanchez RA, Ayala M, Baglivo H, et al. Latin American guidelines on hypertension. Latin American Expert Group. J Hypertens 2009; 27(5): 905-922.

19. Chobanian AV, Bakris GL, Black HR, et al. Seventh report of the Joint National Committee on Prevention, Detection, Evaluation, and Treatment of High Blood Pressure. Hypertension 2003; 42(6): 1206-1252.

20. Malaysian Society of Hypertension, Ministry of Health Malaysia, Academy of Medicine of Malaysia. Clinical practice guidelines. Management of hypertension. 5th edn. Malaysian Society of Hypertension, 2018.
21. Chiang C-E, Wang T-D, Li Y-H, et al. 2010 guidelines of the Taiwan Society of Cardiology for the management of hypertension. J Formos Med Assoc 2010; 109(10): 740-773.

22. Chiang C-E, Wang T-D, Ueng K-C, et al. 2015 guidelines of the Taiwan Society of Cardiology and the Taiwan Hypertension Society for the management of hypertension. J Chin Med Assoc 2015; 78(1): 1-47.

23. Mancia G, Fagard R, Narkiewicz K, et al. 2013 ESH/ESC guidelines for the management of arterial hypertension: the task force for the management of arterial hypertension of the European Society of Hypertension (ESH) and of the European Society of Cardiology (ESC). J Hypertens 2013; 31(7): 1281-1357.

24. Williams B, Mancia G, Spiering W, et al. 2018 ESC/ESH guidelines for the management of arterial hypertension. Eur Heart J 2018; 39(33): 3021-3104.

25. Martin U, Foreman MA, Travis JC, et al. Use of ACE inhibitors and ARBs in hypertensive women of childbearing age. J Clin Pharm Ther 2008; 33(5): 507511.

26. Force RW, Keppel GA, Guirguis-Blake J, et al. Contraceptive methods and informed consent among women receiving medications with potential for adverse fetal effects: a Washington, Wyoming, Alaska, Montana, Idaho (WWAMI) region study. J Am Board Fam Med 2012; 25(5): 661-668.

27. NHS Digital. Read codes. 2018. https://digital.nhs.uk/services/terminology-andclassifications/read-codes (accessed 28 Sep 2020).

28. Pawa J, Robson J, Hull S. Building managed primary care practice networks to deliver better clinical care: a qualitative semi-structured interview study. $\mathrm{Br} J$ Gen Pract 2017; DOI: https://doi.org/10.3399/bjgp17X692597.

29. Petersen I, Welch CA, Nazareth I, et al. Health indicator recording in UK primary care electronic health records: key implications for handling missing data. Clin Epidemiol 2019; 11: 157-167.

30. Lindberg LD, Santelli JS, Desai S. Changing patterns of contraceptive use and the decline in rates of pregnancy and birth among US adolescents, 2007-2014. J Adolesc Health 2018; 63(2): 253-256.

31. Morrical-Kline KA, Walton AM, Guildenbecher TM. Teratogen use in women of childbearing potential: an intervention study. J Am Board Fam Med 2011; 24(3): 262-271

32. Office for National Statistics. Conceptions in England and Wales: 2018. 2020. https://www.ons.gov.uk/peoplepopulationandcommunity/ birthsdeathsandmarriages/conceptionandfertilityrates/bulletins/ conceptionstatistics/2018 (accessed 28 Sep 2020).

33. Schwarz EB, Santucci A, Borrero S, et al. Perspectives of primary care clinicians on teratogenic risk counseling. Birth Defects Res A Clin Mol Teratol 2009; 85(10): 858-863.

34. Medicines and Healthcare products Regulatory Agency. ACE inhibitors and angiotensin II receptor antagonists: recommendations on how to use for breastfeeding. 2014. https://www.gov.uk/drug-safety-update/ace-inhibitors-andangiotensin-ii-receptor-antagonists-recommendations-on-how-to-use-forbreastfeeding (accessed 28 Sep 2020).

35. Jeffries M, Phipps DL, Howard RL, et al. Understanding the implementation and adoption of a technological intervention to improve medication safety in primary care: a realist evaluation. BMC Health Serv Res 2017; 17(1): 196.

36. Schwarz EB, Parisi SM, Handler SM, et al. Clinical decision support to promote safe prescribing to women of reproductive age: a cluster-randomized trial. J Gen Intern Med 2012; 27(7): 831-838.

37. Medicines and Healthcare products Regulatory Agency. Valproate medicines (Epilim $\boldsymbol{\nabla}$, Depakote $\boldsymbol{\nabla}$ ): contraindicated in women and girls of childbearing potential unless conditions of Pregnancy Prevention Programme are met. 2018. https://uww.gov.uk/drug-safety-update/valproate-medicines-epilim-depakotecontraindicated-in-women-and-girls-of-childbearing-potential-unlessconditions-of-pregnancy-prevention-programme-are-met laccessed 28 Sep 2020).

38. Independent Medicines and Medical Devices Safety Review. First do no harm The report of the Independent Medicines and Medical Devices Safety Review. 2020. https://www.immdsreview.org.uk/downloads/IMMDSReview_Web.pdf laccessed 28 Sep 2020). 